\title{
Morphometric measurement of adductor longus and its clinical application: A cadaveric study
}

\author{
Navneet Kour ${ }^{1}$, Vanita Gupta ${ }^{2, *}$, Gaurav Agnihotri ${ }^{3}$, Shalika Sharma $^{4}$, Vikrant Singh $^{5}$ \\ ${ }^{1,5}$ Assistant Professor, ${ }^{2}$ Professor, ${ }^{3,4}$ Associate Professor, ${ }^{\mathbf{1 , 2 , 3 , 4}}$ Dept. of Anatomy, Acharya Shree Chander College of Medical \\ Sciences, Jammu, Jammu \& Kashmir, India ${ }^{5}$ Lecturer, Dept. of Gaestrointestinal Surgery, Government Medical College, Jammu, \\ Jammu \& Kashmir, India
}

*Corresponding Author:

Email: doctorvanita@yahoo.co.in

Received: $17^{\text {th }}$ January, 2018

Accepted: $15^{\text {th }}$ March, 2018

\begin{abstract}
Objectives: A profound knowledge of the anatomical organization of adductor muscle compartment is necessary to understand their functions, and to assist in the development of accurate clinical and biomechanical models. This study aims at providing appropriate morphometric measurements of adductor longus muscle.

Materials and Methods: The present study was conducted on 50 lower limbs. All limbs were fully dissected and measurements were taken with help of a steel tape.

Results: We found Adductor longus muscle in all the 50 dissected lower limbs (100\%). The range of length and width of proximal aponeurosis varied from $4.1-6.8 \mathrm{~cm}$ and $0.8-2.5 \mathrm{~cm}$ respectively. The range of length of fleshy part (muscular belly) varied from $14.4-20.7 \mathrm{~cm}$. The range of length and width of distal aponeurosis varied from $9.8-13.9 \mathrm{~cm}$ and $2.1-4.8 \mathrm{~cm}$ respectively.

Conclusion: Our results would aid educational anatomy dissections, surgical interventions and help in management of many ailments.
\end{abstract}

Keywords: Cadaver, Adductor longus, Morphometry.

\section{Introduction}

A profound knowledge of the anatomical organization of adductor muscle compartment is necessary to understand their functions, and to assist in the development of accurate clinical and biomechanical models. ${ }^{1}$

The adductors (adductor longus, adductor brevis and adductor magnus) originate proximally from the inferior aspect of the body and ramus of the pubis all three muscles insert distally on the femur, from a point beginning on the posterior aspect of the femur proximal to the linea aspera, along the linea aspera, to the adductor tubercle. ${ }^{2}$

The adductor longus is long triangular and relatively thin muscle. Its fibres are narrow proximally and straggle more distally. The anterior branch of the obturator nerve innervates the muscle. It is involved in adduction, external rotation, and anteflexion of the hip joint. ${ }^{3}$ Morphometry of muscles of lower limb has been attempted in the past. ${ }^{4-8}$ Muscle morphometry has helped researchers to improve understanding of muscle anatomy and function, in addition to studying the mechanics of human movement. For example, a direct relationship between a muscle's cross-sectional area (CSA) and its ability to generate force has been a fundamental hypothesis for numerous biomechanical studies. $^{9}$

Elucidation of muscle architecture may provide useful information for selection of muscles used in tendon transfers. To substitute a lost muscle function, the distal tendons of muscles often are transferred from one position to another. ${ }^{10,11}$ Muscle architecture has been studied regarding weight, number and size of muscle fibres. ${ }^{12}$

Reviewing the literature we found an extreme paucity of data pertaining to the details mentioning anatomical characteristics of adductor longus muscle taking into account the length, width of tendon/aponeurosis of origin, the length of its fleshy part (muscle belly), the length, and width of the tendon /aponeurosis of insertion. The present work attempts to provide a detailed morphometric profile of the adductor longus muscle.

\section{Materials and Methods}

Fifty lower limbs from 25 phenol embalmed adult cadavers were dissected in the Department of Anatomy. Out the fifty, forty - six were male limbs (23 cadevers) and four were female limbs (two cadevers). The cadavers were labelled from 1 to 25 with suffix $R$ (Right) or L (Left). The adductor longus muscle was exposed and its origin and insertion were traced on the hip bone and femur as per the dissection steps provided by Cunningham's Manual of Practical Anatomy (Romanes, 1986). Each measurement was taken using a standard measuring tape.

The origin of muscle from the front of body of the pubis immediately below the pubic crest to the start of fleshy part was traced. The length of proximal aponeurosis/tendon was considered from origin of the 
tendon upto the point where fleshy muscle fibres commenced (Fig. 1). The width of proximal aponeurosis of muscle on the body of pubis was also measured (Fig. 2). The muscle was then divided transversely near its origin. The proximal part of muscle was turned towards the distal part of femur. The aponeurotic insertion of the muscle onto the linea aspera of the femur was finally traced. The length of distal aponeurosis on the linea aspera was measured from the point where fleshy fibres ceased (Fig. 3). The width of distal aponeurosis was measured transversely from the linea aspera (Fig. 4). The length of the fleshy part of the muscle was also measured (Fig. 5).

Means and standard deviations of these measurements were calculated. All statistical analysis was done using SPSS.

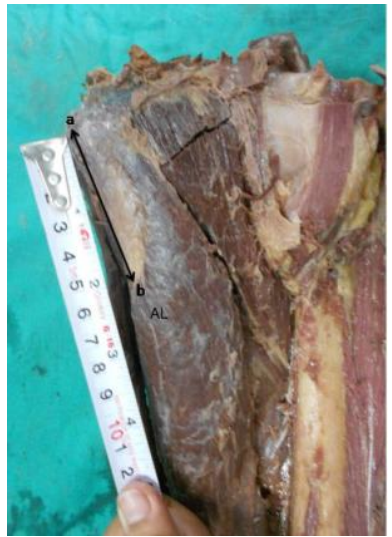

AL: Adductor longus

Distance ab: length of proximal aponeurosis of adductor longus

Fig.1: Measurement of length of proximal aponeurosis of Adductor Longus (left limb)

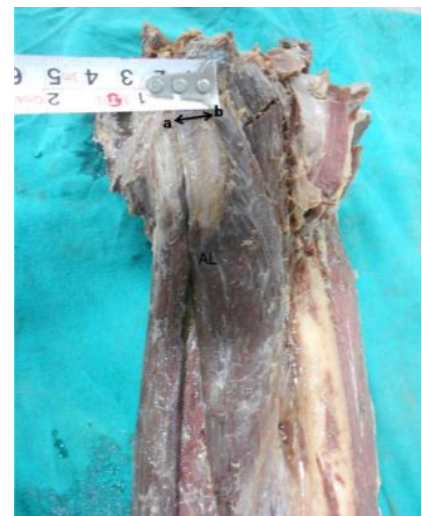

AL: Adductor longus

Distance ab: Width of proximal aponeurosis of adductor longus

Fig. 2: Measurement of width of proximal aponeurosis of Adductor Longus (left limb)

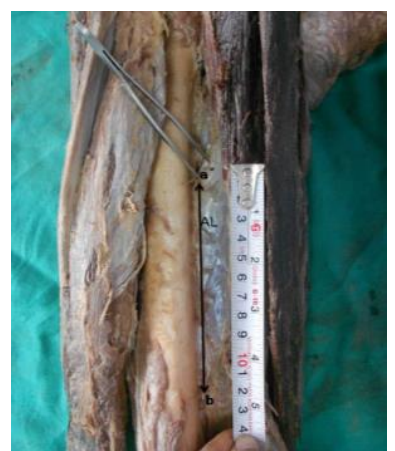

AL: Adductor longus

Distance ab: length of distal aponeurosis of adductor longus

Fig. 3: Measurement of length of distal aponeurosis of the Adductor Longus (Right limb)

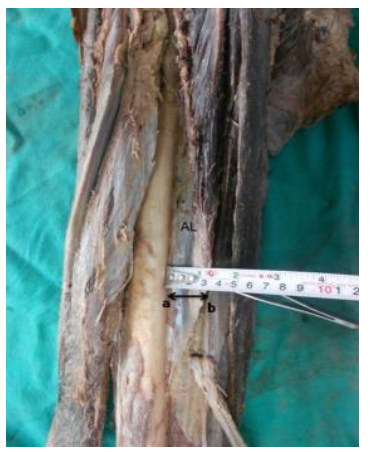

AL: Adductor Longus

Distance ab: width of distal aponeurosis of adductor longus

Fig. 4: Measurement of width of distal aponeurosis of the Adductor Longus (Right Limb)

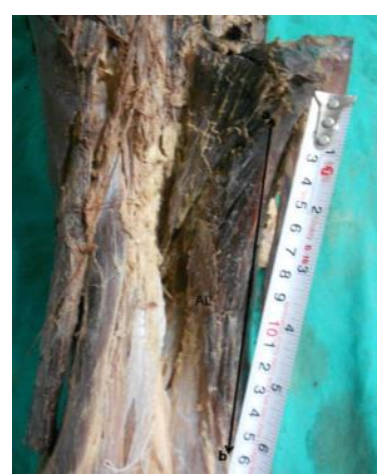

AL: Adductor longus

Distance ab: length of fleshy part of adductor longus

Fig.5: Measurement of fleshy part of Adductor Longus (Right limb) 
Table 1: Mean values (in cms) and standard deviation of various parameters of Adductor Longus (50 limbs)

\begin{tabular}{|c|l|c|c|}
\hline S. N. & \multicolumn{1}{|c|}{ Parameters } & $\begin{array}{c}\text { Mean } \\
\text { values }\end{array}$ & $\begin{array}{c}\text { Standard } \\
\text { deviation }\end{array}$ \\
\hline 1 & Fleshy part & 17.19 & 1.734788 \\
\hline 2 & Length of the proximal aponeurosis & 5.246 & 0.715773 \\
\hline 3 & Width of the proximal aponeurosis & 1.354 & 0.356405 \\
\hline 4 & Length of the distal aponeurosis & 12.582 & 1.221022 \\
\hline 5 & Width of the distal aponeurosis & 3.018 & 0.538209 \\
\hline
\end{tabular}

Table depicting the values for the total sample i.e. 50 limbs from 25 cadavers.

Table 2: Mean values and standard deviation of various parameters of Adductor Longus in males (46 limbs)

\begin{tabular}{|c|l|c|c|}
\hline S. N. & \multicolumn{1}{|c|}{ Parameters } & $\begin{array}{c}\text { Mean } \\
\text { values }\end{array}$ & $\begin{array}{c}\text { Standard } \\
\text { deviation }\end{array}$ \\
\hline 1 & Fleshy part length & 17.3 & 1.726782 \\
\hline 2 & Length of the distal aponeurosis & 5.308696 & 0.692444 \\
\hline 3 & Width of the distal aponeurosis & 1.373913 & 0.362359 \\
\hline 4 & $\begin{array}{l}\text { Length of the proximal } \\
\text { aponeurosis }\end{array}$ & 12.66522 & 1.137095 \\
\hline 5 & Width of the proximal aponeurosis & 3.030435 & 0.55812 \\
\hline
\end{tabular}

Table 3: Mean values and standard deviation of various parameters of Adductor Longus in females (4 limbs)

\begin{tabular}{|c|l|c|c|}
\hline S. N. & \multicolumn{1}{|c|}{ Parameters } & $\begin{array}{c}\text { Mean } \\
\text { values }\end{array}$ & $\begin{array}{c}\text { Standard } \\
\text { deviation }\end{array}$ \\
\hline 1 & Fleshy part & 15.925 & 1.452297 \\
\hline 2 & Length of the distal aponeurosis & 4.525 & 0.65 \\
\hline 3 & Width of the distal aponeurosis & 1.125 & 0.170783 \\
\hline 4 & $\begin{array}{l}\text { Length of the proximal } \\
\text { aponeurosis }\end{array}$ & 11.625 & 1.905037 \\
\hline 5 & Width of the proximal aponeurosis & 2.875 & 0.170783 \\
\hline
\end{tabular}

\section{Observations}

We found Adductor longus muscle in all the 50 dissected lower limbs (100\%). In all the 50 limbs the origin and the insertion of the muscle was according to the typical anatomical pattern .All these were recorded as shown in table 1 . The range of length of proximal aponeurosis varied from $4.1-6.8 \mathrm{~cm}$ and the range of width of proximal aponeurosis varied from $0.8-2.5 \mathrm{~cm}$. The range of length of fleshy part (muscular belly) varied from $14.4-20.7 \mathrm{~cm}$. The range of length of distal aponeurosis varied from $9.8-13.9 \mathrm{~cm}$ and the range of width of distal aponeurosis varied from 2.1 $4.8 \mathrm{~cm}$. The results of the mean values in both males and females are depicted in tables 2-4.

\section{Discussion}

Human bipedalism is an exclusive character with which we are able to stand and walk with trunk upright and knees nearly straight. ${ }^{13}$ The adductor muscles of medial compartment of thigh have an important role in balancing and stabilizing the trunk on the lower limb during walking. ${ }^{2}$ These muscles adduct the femur and counteract the rotation of the pelvis, especially during the double support phase of gait, when the anterior lower extremity is flexed and the posterior lower extremity is extended at hip. ${ }^{14}$

We could come across very few studies wherein research work has been done regarding morphometric analysis of adductor muscles of the thigh. ${ }^{15-18}$ The observations in these studies were based on non invasive techniques such as MRI and CT. Reviewing the literature we found that very few studies have been conducted on cadavers giving details of morphometry of these muscles. ${ }^{19,20}$ This gave us an impetus to concentrate our research on cadavers restricting to measurements pertaining to Adductor Longus.

After having dissected the region carefully, the morphometric and statisical analysis of the muscle was done. It was observed that both the origin and the insertion of the muscle was not exactly tendinous but the fibres formed an aponeurosis. The mean lengths of the fleshy part (muscle belly) was $17.3 \mathrm{cms}$ and the distal aponeurotic part (contractile part) was $5.3 \mathrm{cms}$. Not much could be assessed from the findings of female patients due to the paucity of female cadavers. These observations of ours are different from what has been mentioned in standard textbooks of anatomy.

Adductor longus injuries are serious and can be missed many a times. The muscle is known to tear from its insertion. ${ }^{21}$ Adductor longus tendon tear and strains have been found to occur in athletes. ${ }^{22,23}$ Subtotal or 
total ruptures of the adductor longus muscle are rare. ${ }^{24-}$ 29

Insertional tendinopathy of the adductor longus is a common and problematic condition in elite athletes and may lead to rupture. ${ }^{22}$ Treatment of these would include transfer of tendon wherein a profound knowledge of muscle and tendon length is important.

Tendon transfer and tendon repair surgeries are being attempted by surgeons..$^{9,10}$ It is here that Aponeurotic attachments especially the insertions can pose difficulties. Thus our detailed accounts of measurements can prove to be useful.

Athletes diagnosed with rupture of adductor longus tendon, acute repair with suture anchors is the treatment of choice. Gracilis and adductor longus are located in the same region of the human thigh, and the two are supplied by the same vascular source and nerve. Both are long strap muscles with good excursion. Overall, these characteristics make the two muscles candidates for the development of surgical procedures for double functioning free muscle transplantation (DFFMT) based on single vascular anastomosis. ${ }^{23}$ A detailed morphometric analysis would certainly be of help to the surgeons doing such work.

Sport surgeons resort to adductor release and tenotomy only if other rehabilitative procedures fail to cure the patient of pain and debility. ${ }^{20}$

\section{Conclusion}

Findings of the present study shall assist in understanding the muscle functions. Also as morphological features are in direct correlation with their function and this data might prove useful in further research in the field of mycology and kinesiology. The knowledge of such morphometric analysis may be helpful to general surgeons and orthopaedic surgeons in the management of adductor longus injuries, tendon transfers and muscle transdisposition.

\section{References}

1. Singh H, Kour R and Gupta N. "Morphometric Study of Gracilis Muscle and its Role in Clinical Reconstruction". Journal of Anatomical Society of India.(2011) 60, 202-6.

2. Standring S, Grays Anatomy: The Anatomical Basis of Clinical Practice. $39^{\text {th }}$ ed. Edinburg: Churchill Livingstone. (2005),1465-66.

3. Kimmenade VD, Bergen V, DeurzenV and Verhagen R. "A Rare Case of Adductor Longus Muscle." Case Reports in Orthopedics (2015), Article ID 840540, 4 pages doi:10.1155/2015/840540.

4. Friedrich JA, Brand RA. "Technical Note: muscle fibre architecture in the human lower limb". Journal of Biomechanics. (1990) 23,91-5.

5. Wickiewicz TL, Roy RR, Powel PL, Edgerton VR. "Muscle Architecture of human lower limb." Clinical Orthopaedics and Related Research (1983) 178,275-83.
6. Hasegawa M. "On the myofibrous organization of human iliopsoas.” Journal Showa Med Assoc (1987) 47, 833-42.

7. Kataoka J. "Comparative studies on muscle structure of triceps surae and $\mathrm{m}$. plantaris in man and monkey." J Showa Med Assoc (1987)47,851-861.

8. Oohara K. "Myofibrous organization of human hamstring muscles." J Showa Med Assoc (1991) 51,1518 .

9. Haxton HA. "Absolute muscle force in the ankle flexors of man." Journal of Physiology (1944) 103, 267-73.

10. Boyes JH. "Tendon transfers for radial palsy." Bull Hosp Jt Dis (1960) 21,97-105.

11. Riordan DC. "Tendon transfers for median, ulnar, or radial nerve palsy." J Bone Joint Surg (1968) 50B, 441-9.

12. Ito J, Moriyama $\mathrm{H}$, Innokuchi $\mathrm{S}$ and Gotu N. "Human lower limb muscles: An Evaluation of Weight and fibre size.” Okijiimas Folia Anat. J Japan.( August 2003) 80, 2 3.

13. Bhargava KN, Sanyal KP, Bhargava SN. "Lateral musculature of the leg as seen in hundred Indian cadavers." Ind J Med Sci.(1961) 15,181-5.

14. Tuite DJ, Finegan PJ, Saliaris AP, Renstrom PA, Donne B, O’Brien M. "Anatomy of the proximal musculotendinous junction of the adductor longus muscle.” Knee Surg Sports Traumatol Arthrosc. (1998) 6, 134-7.

15. Scott H, Engstrom CM and Loebge. "Morphometry of human thigh muscles. Determination of fascicle architecture by magnetic resonance imaging." Journal of Anatomy. (1993) 182, 249-57.

16. Engstrom CM,Loeb GE, Reidi JG, Forrest WJ and Avruch L. "Morphometry of the human thigh muscles. A comparison between anatomical sections and computer tomographic and magnetic resonance images." Journal of Anatomy.(1991) 176,139-56.

17. Rugg SG, Gregor RJ, Mandelbaum BR, Chiu L. "In vivo moment arm calculations at the ankle using magnetic resonance imaging (MRI)." Journal of Biomechanics.(1990) 23,494-501.

18. Spoor CW, Vanleeuwen JL. "Technical note: knee muscle moment arms from MRI and from tendon travel." Journal of Biomechanics. (1992) 25, 201-6.

19. Maughan RJ, Watson JS, Weir J. Strength and crosssectional area of human skeletal muscle. Journal of Physiology. (1983) 338,37-49.

20. Ito J. "Morphologica analysis of human lower extremity based on relative muscle weight" Okajimas Folia Anat Japan. (1996)73,247-52.

21. Banks DBA, MacLennan I, Banks AJ. "Adductor longus ruptures in elite sportsmen - pitfalls of surgical repair: a report of two cases, case report". BMJ Case Reports 24 June (2013) doi:10.1136/bcr-2013-010073.

22. Rizio L, Salvo JP, Schurhoff MR, Uribe JW. "Adductor longus rupture in professional football players: acute repair with suture anchors." A report of two cases. Am J Sports Med (2004) 32,243-5.

23. Peterson L and Stener B. "Old total rupture of the adductor longus muscle. A report of seven cases. Acta Orthopaedica Scandinavica." (1976) 47(6), 653-7.

24. Vogt S, Ansah P, and Imhoff AB. "Complete osseous avulsion of the adductor longus muscle: acute repair with three fiberwire suture anchors." Archives of Orthopaedic and Trauma Surgery. (2007) 127, 613-5.

25. Sangwan SS, Aditya A, and Siwach RC. "Isolated traumatic rupture of the adductor longus muscle. Indian Journal of Medical Sciences".(1994) 48(8),186-7.

26. Schlegel TF, Bushnell BD, Godfrey J, and Boublik M. "Success of nonoperative management of adductor longus 
tendon ruptures in National Football League athlete". The American Journal of Sports Medicine. (2009) 37(7), 1394-9.

27. Feeley BT, Powel JW, Muller MS, Barnes RP, Warren RF and Kelly BT. "Hip injuries and labral tears in the national football league". American Journal of Sports Medicine.( 2008) 36(11), 2187-95.

28. Aerts BRJ, Plaisier PW, and Jakma TSC. "Adductor longus tendon rupture mistaken for incarcerated inguinal hernia. Injury". (2014) 45(3),639-41.

29. Akermark C and Johansson C. "Tenotomy of the adductor longus tendon in the treatment of chronic groin pain in athletes". The American Journal of Sports Medicine.(1992) 20(6), 640-3.

30. Shah R, Tulsiani S, Harimoorthy V, Mathur A, Choudhury N. "A meta-analysis on the clinical effectiveness of transversus abdominis plane block" Journal of Clinical Anesthesia (2011) 23,7-14. 